Check for updates

Cite this: RSC Adv., 2019, 9, 18183

Received 6th April 2019

Accepted 3rd June 2019

DOI: 10.1039/c9ra02580d

rsc.li/rsc-advances

\section{Structural exploration of rhodium catalysts and their kinetic studies for efficient parahydrogen- induced polarization by side arm hydrogenation $\uparrow$}

\author{
Marino Itoda, ${ }^{a}$ Yuki Naganawa, (D) *ab Makoto Ito, ${ }^{a}$ Hiroshi Nonaka iD a \\ and Shinsuke Sando (iD *ac
}

Parahydrogen-induced polarization (PHIP) is a rapid and cost-effective hyperpolarization technique using transition metal-catalysed hydrogenation with parahydrogen. We examined rhodium catalysts and their kinetic studies, rarely considered in the research of current PHIP. It emerged that rhodium complexes with electron-donating bisphosphine ligands, with a dicyclohexylphosphino group, appear to be more effective than conventional rhodium catalysts.

\section{Introduction}

Nuclear magnetic resonance (NMR) spectroscopy is one of the attractive techniques for non-invasive biological analysis. However, in vivo analysis at a molecular level by NMR spectroscopy is often problematic because of the intrinsic low sensitivity. Hyperpolarization techniques have been developed to enhance the intensity of NMR signals of target nuclei dramatically. Theoretically in the case of ${ }^{13} \mathrm{C}$ nuclei, hyperpolarization should enhance intensities of NMR signals up to $10^{5}$ times more than in the thermal equilibrium. ${ }^{1}$ Among various protocols, the dissolution dynamic nuclear polarization (dDNP) method has become a mainstream technique to achieve high polarization levels, although several unsolved issues do remain, such as the requirement for expensive equipment and prolonged operating times of several hours. ${ }^{2}$

Meanwhile, parahydrogen-induced polarization (PHIP), ${ }^{3}$ in addition to signal amplification by reversible exchange (SABRE),${ }^{4}$ has drawn increasing attention as an easy and costeffective hyperpolarization technique. PHIP utilizes transition metal-catalysed hydrogenation of carbon-carbon unsaturated bonds in precursor molecules with parahydrogen, the spin isomer of molecular hydrogen with antiparallel nuclear spins (Scheme 1). The rapid decay of hyperpolarization generally proceeds through spin-lattice

\footnotetext{
${ }^{a}$ Department of Chemistry and Biotechnology, Graduate School of Engineering, The University of Tokyo, 7-3-1 Hongo, Bunkyo-ku, Tokyo, 113-8656, Japan. E-mail: ssando@chembio.t.u-tokyo.ac.jp

${ }^{b}$ Interdisciplinary Research Center for Catalytic Chemistry, National Institute of Advanced Industrial Science and Technology (AIST), 1-1-1 Higashi, Tsukuba, Ibaraki, 305-8565, Japan. E-mail: yuki.naganawa@aist.go.jp

${ }^{c}$ Department of Bioengineering, Graduate School of Engineering, The University of Tokyo, 7-3-1 Hongo, Bunkyo-ku, Tokyo, 113-8656, Japan

$\dagger$ Electronic supplementary information (ESI) available. See DOI: 10.1039/c9ra02580d
}

relaxation, and thus it is preferable that the polarization is transferred from ${ }^{1} \mathrm{H}$ to other heteronuclei such as ${ }^{13} \mathrm{C}$ and ${ }^{15} \mathrm{~N}$ with larger $T_{1}$, by field cycling or using radio frequency pulse, where the hyperpolarized spin state can be retained for longer periods of time. ${ }^{5}$ Therefore, the first hydrogenation with parahydrogen is regarded as the dominant step of PHIP to realize sufficient polarization levels. Hyperpolarization levels are positively correlated with the reaction rate of the hydrogenation reaction; therefore, this key step should be completed as soon as possible with highly active transition metal catalysts.

Regarding the choice of metal catalysts, homogeneous rhodium complexes have been applied to hydrogenation in PHIP because the pairwise addition to unsaturated bonds must take place to retain the initial spin character of parahydrogen. ${ }^{6,7}$ Commercially available $[\mathrm{Rh}(\mathrm{nbd})(\mathrm{dppb})] \mathrm{BF}_{4}$ (1) (nbd $=2,5$-norbornadiene, $\mathrm{dppb}=1,4$-bis(diphenylphosphino)butane) has been employed in typical PHIP experiments, although the catalytic activity of this conventional cationic rhodium complex $\mathbf{1}$ (see Fig. 1a) is sometimes inadequate. For example, Chekmenev and co-workers ${ }^{8}$ reported PHIP experiments of $\left[1-{ }^{13} \mathrm{C}\right]$ vinyl acetate (VA) with $\mathbf{1}$, wherein high hydrogen pressure was required to complete the hydrogenation within a few seconds. In this case, hydrogenation of $80 \mathrm{mM}$ VA solution in methanol- $d_{4}$ at $40{ }^{\circ} \mathrm{C}$ under standard pressure $(1 \mathrm{bar})$ was not completed after $100 \mathrm{~s}^{8 a}$

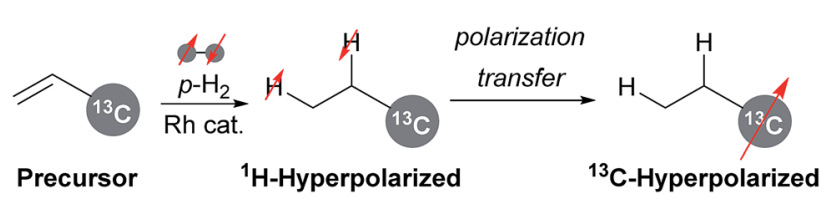

Scheme 1 Experimental concept of PHIP. 
(a)

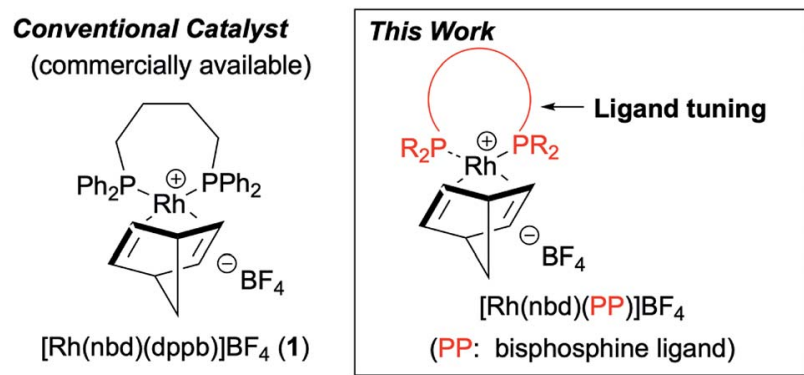

(b)

$$
\left\{\begin{array}{l}
\mathrm{n}=1 \\
{[\mathrm{Rh}(\mathrm{nbd})(\mathrm{dcpe})] \mathrm{BF}_{4}(2)} \\
\mathrm{n}=2 \\
{\left[\mathrm{Rh}(\mathrm{nbd})(\mathrm{dcpp}) \mathrm{BF}_{4}(3)\right.} \\
\mathrm{n}=3 \\
{\left[\mathrm{Rh}(\mathrm{nbd})(\mathrm{dcpb}) \mathrm{BF}_{4}(4)\right.}
\end{array}\right.
$$

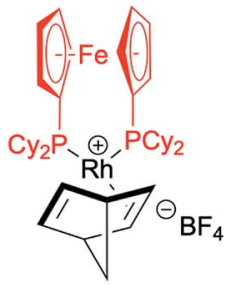

$[\mathrm{Rh}(\mathrm{nbd})(\mathrm{dcpf})] \mathrm{BF}_{4}(\mathbf{5})$

Fig. 1 (a) Structural exploration of conventional rhodium complex 1. (b) Rhodium complexes 2-5 selected based on the screening of ligands.

In the field of organometallic chemistry, the development of various rhodium catalysts for hydrogenation has thus far been devoted to the achievement of high reactivity and efficiency. In contrast, such careful investigations on rhodium catalysts have rarely been considered for PHIP experiments, ${ }^{9}$ especially for PHIP by side arm hydrogenation (PHIP-SAH).$^{10}$ PHIP-SAH is a promising method which can hyperpolarize carboxylic acid such as pyruvic acid, an attractive substrate for hyperpolarized magnetic resonance imaging (MRI). ${ }^{\mathbf{1 1}}$ We therefore focused our attention and efforts on the structural exploration of $[\mathrm{Rh}(\mathrm{nbd})(\mathrm{PP})] \mathrm{BF}_{4} \quad(\mathrm{PP}=$ bisphosphine ligand) and kinetic studies to improve the efficiency of PHIP experiments (see Fig. 1a).

\section{Experimental}

\section{Synthesis}

General information. Reagents and solvents were purchased from standard suppliers and used without further purification. NMR spectra were measured using JEOL ECS400 spectrometer and Bruker Ascend 500 NMR spectrometer. Chloroform- $d_{1}$ (7.26 ppm) and methanol- $d_{4}(3.31 \mathrm{ppm})$ were used as the internal standards for ${ }^{1} \mathrm{H}$ NMR. Chloroform- $d_{1}(77.2 \mathrm{ppm})$ and methanol- $d_{4}(49.0 \mathrm{ppm})$ were used as the internal standards for ${ }^{13} \mathrm{C}$ NMR. Phosphoric acid (0.0 ppm) was used as the external standard for ${ }^{31} \mathrm{P}$ NMR. ESI mass spectra (MS) were measured using Bruker micrOTOF II.

Synthesis of $[\mathbf{R h}(\mathbf{n b d})(\mathbf{d c p e})] \mathbf{B F}_{4}(2) .\left[\mathrm{Rh}(\mathrm{nbd})_{2}\right] \mathrm{BF}_{4}(329 \mathrm{mg}$, $0.881 \mathrm{mmol}$ ) and 1,2-bis(cyclohexylphosphino)ethane (372 mg, $0.881 \mathrm{mmol})$ were dissolved in dichloromethane $(17 \mathrm{~mL})$. The mixture was stirred for $7 \mathrm{~h}$ at room temperature, and then $n$ hexane was poured into the solution to afford an orange precipitate. The precipitate was filtered and washed with $n$ - hexane and dried in vacuo. The product was recrystallized from ethanol to give red crystal $(252 \mathrm{mg}, 41 \%)$.

${ }^{1} \mathrm{H}$ NMR $\left(\mathrm{CDCl}_{3}, 400 \mathrm{~Hz}\right) \delta=5.54(\mathrm{~s}, 4 \mathrm{H}), 4.23(\mathrm{~s}, 2 \mathrm{H}), 2.03-$ $1.70(\mathrm{~m}, 20 \mathrm{H}), 1.39-1.02(\mathrm{~m}, 30 \mathrm{H}) ;{ }^{13} \mathrm{C} \mathrm{NMR}\left(\mathrm{CDCl}_{3}, 125 \mathrm{MHz}\right)$ $\delta=85.4,71.7,55.7,35.4-35.7(\mathrm{~m}), 29.5,29.0,27.1(\mathrm{t}, J=4.7 \mathrm{~Hz})$, $26.7(\mathrm{t}, J=4.0 \mathrm{~Hz}), 26.4,25.9,21.1(\mathrm{t}, J=16 \mathrm{~Hz}) ;{ }^{31} \mathrm{P} \mathrm{NMR}$ $\left(\mathrm{CDCl}_{3}, 162 \mathrm{~Hz}\right) \delta=70.2(\mathrm{~d}, J=153 \mathrm{~Hz}) ; \mathrm{HRMS}(\mathrm{ESI}): \mathrm{m} / z$ calc. for $\mathrm{C}_{33} \mathrm{H}_{56} \mathrm{P}_{2} \mathrm{Rh}^{+}\left[\mathrm{M}-\mathrm{BF}_{4}{ }^{-}\right]^{+}=617.2907$, found $=617.2900$.

Synthesis of $[\mathbf{R h}(\mathbf{n b d})(\mathbf{d c p p})] \mathrm{BF}_{4}(3) .\left[\mathrm{Rh}(\mathrm{nbd})_{2}\right] \mathrm{BF}_{4}(63.4 \mathrm{mg}$, $0.170 \mathrm{mmol}$ ) and 1,3-bis(cyclohexylphosphino)propane bis(tetrafluoroborate) (104 mg, $0.170 \mathrm{mmol}$ ) were dissolved in dichloromethane $(3.5 \mathrm{~mL}) . N, N$-diisopropylethylamine $(29.5 \mu \mathrm{L}$, $0.339 \mathrm{mmol}$ ) was added and the mixture was stirred for $5 \mathrm{~h}$ at room temperature. Then, $n$-hexane was poured into the solution to afford an orange precipitate. The precipitate was filtered and washed with $n$-hexane and dried in vacuo. The product was recrystallized from methanol to give red crystal $(89.4 \mathrm{mg}, 73 \%)$.

${ }^{1} \mathrm{H} \mathrm{NMR}\left(\mathrm{CDCl}_{3}, 400 \mathrm{~Hz}\right) \delta=5.18(\mathrm{~s}, 4 \mathrm{H}), 4.14(\mathrm{~s}, 2 \mathrm{H}), 2.20-$ $1.14(\mathrm{~m}, 52 \mathrm{H}) ;{ }^{13} \mathrm{C} \mathrm{NMR}\left(\mathrm{CDCl}_{3}, 100 \mathrm{MHz}\right) \delta=80.2,70.7,54.4$, $36.9(\mathrm{t}, J=11 \mathrm{~Hz}), 30.4,28.7,27.5(\mathrm{t}, J=5.7 \mathrm{~Hz}), 26.8(\mathrm{t}, J=4.8$ $\mathrm{Hz}), 26.0,22.5,17.8(\mathrm{t}, J=13.8 \mathrm{~Hz}) ;{ }^{31} \mathrm{P} \mathrm{NMR}\left(\mathrm{CDCl}_{3}, 162 \mathrm{~Hz}\right) \delta=$ $16.3\left(\mathrm{~d}, J=148 \mathrm{~Hz}\right.$ ); HRMS(ESI): $m / z$ calc. for $\mathrm{C}_{34} \mathrm{H}_{58} \mathrm{P}_{2} \mathrm{Rh}^{+}[\mathrm{M}-$ $\left.\mathrm{BF}_{4}^{-}\right]^{+}$631.3063, found 631.3050.

Synthesis of $[\mathbf{R h}(\mathbf{n b d})(\mathbf{d c p b})] \mathrm{BF}_{4}(\mathbf{4}) .\left[\mathrm{Rh}(\mathrm{nbd})_{2}\right] \mathrm{BF}_{4}(374 \mathrm{mg}$, $1.00 \mathrm{mmol}$ ) and 1,4-bis(cyclohexylphosphino)butane (451 mg, $1.00 \mathrm{mmol})$ were dissolved in dichloromethane $(20 \mathrm{~mL})$. The mixture was stirred for $6 \mathrm{~h}$ at room temperature and then $n$ hexane was poured into the solution to afford an orange precipitate. The precipitate was filtered and washed with $n$ hexane and dried in vacuo. The product was recrystallized twice from methanol to give red crystal (589 $\mathrm{mg}, 80 \%)$.

${ }^{1} \mathrm{H}$ NMR $\left(\mathrm{CDCl}_{3}, 400 \mathrm{~Hz}\right) \delta=4.93(\mathrm{~s}, 4 \mathrm{H}), 4.09(\mathrm{~s}, 2 \mathrm{H}), 2.15$ $(\mathrm{m}, 4 \mathrm{H}), 2.03-1.60(\mathrm{~m}, 30 \mathrm{H}), 1.46-1.18(\mathrm{~m}, 20 \mathrm{H}) ;{ }^{13} \mathrm{C} \mathrm{NMR}$ $\left(\mathrm{CDCl}_{3}, 100 \mathrm{MHz}\right) \delta=76.7-77.3(\mathrm{~m}), 69.8,53.7,36.7(\mathrm{t}, J=11$ $\mathrm{Hz}), 31.0,28.7,27.6(\mathrm{t}, J=5.7 \mathrm{~Hz}), 26.9(\mathrm{t}, J=4.3 \mathrm{~Hz}), 26.1,24.2$, $17.1(\mathrm{t}, J=11 \mathrm{~Hz}) ;{ }^{31} \mathrm{P}$ NMR $\left(\mathrm{CDCl}_{3}, 162 \mathrm{~Hz}\right) \delta=27.7(\mathrm{~d}, J=153$ $\mathrm{Hz})$; $\mathrm{HRMS}(\mathrm{ESI}): \mathrm{m} / \mathrm{z}$ calc. for $\mathrm{C}_{35} \mathrm{H}_{60} \mathrm{P}_{2} \mathrm{Rh}^{+}\left[\mathrm{M}-\mathrm{BF}_{4}{ }^{-}\right]^{+}=$ 645.3220, found 645.3208.

Synthesis of $[\mathbf{R h}(\mathbf{n b d})(\mathbf{d c p f})] \mathrm{BF}_{4}(5) .\left[\mathrm{Rh}(\mathrm{nbd})_{2}\right] \mathrm{BF}_{4}(66.7 \mathrm{mg}$, $0.178 \mathrm{mmol}$ ) and 1,1'-bis(cyclohexylphosphino)ferrocene (105 mg, $0.181 \mathrm{mmol})$ were dissolved in dichloromethane $(3.5 \mathrm{~mL})$. The mixture was stirred for $6.5 \mathrm{~h}$ at room temperature and then $n$ hexane was poured into the solution to afford an orange precipitate. The precipitate was filtered and washed with $n$-hexane and dried in vacuo. The product was recrystallized twice from methanol to give red crystal (92.4 mg, 60\%).

${ }^{1} \mathrm{H} \mathrm{NMR}\left(\mathrm{CDCl}_{3}, 400 \mathrm{~Hz}\right) \delta=5.06(\mathrm{~s}, 4 \mathrm{H}), 4.47(\mathrm{~s}, 4 \mathrm{H}), 4.29(\mathrm{~s}$, $4 \mathrm{H}), 4.15(\mathrm{~s}, 2 \mathrm{H}), 2.33(\mathrm{~m}, 4 \mathrm{H}), 2.18-1.06(\mathrm{~m}, 42 \mathrm{H}) ;{ }^{13} \mathrm{C} \mathrm{NMR}$ $\left(\mathrm{CDCl}_{3}, 100 \mathrm{MHz}\right) \delta=75.4,73.5,72.0,69.6,53.7,37.1(\mathrm{t}, J=10$ $\mathrm{Hz}), 30.0,30.0,27.6(\mathrm{t}, J=6.2 \mathrm{~Hz}), 26.7(\mathrm{t}, J=4.8 \mathrm{~Hz}), 26.0 ;{ }^{31} \mathrm{P}$ NMR $\left(\mathrm{CDCl}_{3}, 162 \mathrm{~Hz}\right) \delta=29.8(\mathrm{~d}, J=162 \mathrm{~Hz})$; HRMS(ESI): $m / z$ calc. for $\mathrm{C}_{41} \mathrm{H}_{60} \mathrm{FeP}_{2} \mathrm{Rh}\left[\mathrm{M}-\mathrm{BF}_{4}{ }^{-}\right]^{+}$773.2575, found 773.2551.

\section{Ligand screening}

General information. Reagents and solvents were purchased from standard suppliers and used without further purification. ${ }^{1} \mathrm{H}$ 
Table 1 Result of ligand screening in hydrogenation of $\mathrm{VA}^{a}$

Entry

${ }^{a}$ Hydrogen $\left(20 \mathrm{~mL} \mathrm{~min}^{-1}, 1 \mathrm{~atm}\right)$ was bubbled into a solution of VA in methanol- $d_{4}(150 \mathrm{mM})$ with $5 \mathrm{mM}$ of rhodium catalyst in an NMR tube for $30 \mathrm{~s}$ at $50{ }^{\circ} \mathrm{C}$. ${ }^{b}$ The conversion rate was determined by ${ }^{1} \mathrm{H}$ NMR analysis. n.d. $=$ not detected.

NMR spectra were measured using JEOL ECS400 spectrometer. Hydrogen flowing was controlled using EYELA MFC-1000- $\mathrm{H}_{2}$.

Ligand screening for vinyl acetate. Ligand $(3.5 \mu \mathrm{mol}$ or 7.0 $\mu \mathrm{mol}$ for $\mathrm{PPh}_{3}$ and $\left.\mathrm{PCy}_{3}\right)$ and $\left[\mathrm{Rh}(\mathrm{nbd})_{2}\right] \mathrm{BF}_{4}(3.5 \mu \mathrm{mol})$ were dissolved in dichloromethane $(200 \mu \mathrm{L})$ and the mixture was vortexed for $90 \mathrm{~min}$. The solvent was removed under reduced pressure. The residue was re-dissolved in methanol- $d_{4}(690 \mu \mathrm{L})$. Vinyl acetate $(9.7$ $\mu \mathrm{L}$ ) was added to the mixture (final concentration $150 \mathrm{mM}$ ), which was then transferred into an NMR tube. The mixture in an NMR tube was warmed in a water bath at $50{ }^{\circ} \mathrm{C}$ for $10 \mathrm{~s}$ and hydrogen $(20$
$\mathrm{mL} \min ^{-1}$ ) was bubbled into the mixture at $50{ }^{\circ} \mathrm{C}$ for $30 \mathrm{~s}$ under ordinary pressure. Conversion of vinyl acetate was determined by ${ }^{1} \mathrm{H}$ NMR.

\section{Hydrogenation kinetics}

General information. Reagents and solvents were purchased from standard suppliers and used without further purification. UV-vis spectra were measured using JASCO V-630 UV-VIS spectrophotometer. NMR spectra were measured using JEOL ECS400 spectrometer. Hydrogen flowing was controlled using EYELA MFC-1000- $\mathrm{H}_{2}$.

Molar extinction coefficient before hydrogenation. $5 \mathrm{mM}$ stock solutions of catalysts were prepared with HPLC-grade methanol. The stock solution was diluted to $0.5,0.4,0.3,0.2$ and $0.1 \mathrm{mM}$, respectively. Molar extinction coefficient at absorption maximum around 470-480 $\mathrm{nm}$ (ref. 12) was determined from an inclination of an approximate line in concentration-UV absorbance plot.

Molar extinction coefficient after hydrogenation. $5 \mathrm{mM}$ of catalyst solutions were set into a disposable UV cell with a cap. Hydrogen was bubbled at room temperature under ordinary pressure until activation was completed. (Bubbling duration was roughly estimated using $5 \mathrm{mM}$ catalyst in methanol- $d_{4}$.) After the activation of 5.0, 4.0, 3.0, 2.0 and $1.0 \mathrm{mM}$ (cat 1, 2 and 4), 2.5, 2.0, 1.5, 1.0 and $0.5 \mathrm{mM}$ (cat 3), 1.25, 1.0, 0.75, 0.5 and $0.25 \mathrm{mM}$ (cat 5) of each catalyst solution, UV-vis spectra of these activated solutions were measured. Apparent molar extinction coefficient was determined from an inclination of an approximate line in concentration-absorbance plot.

Determination of activation rates. $5 \mathrm{mM}$ stock solutions of catalysts were prepared with HPLC-grade methanol. The stock solution was diluted to $0.5 \mathrm{mM}$ in a UV quartz cell with septum screw cap. The cell was degassed and filled with 1 atm of hydrogen. Immediately after replacement with hydrogen, UV-vis absorbance measurement was started. Linear approximation was applied during 30-90 s, because the absorbance wasn't stable during $0-30 \mathrm{~s}$.

Determination of TOF for vinyl acetate. $5 \mathrm{mM}$ of catalyst solution in methanol- $d_{4}$ containing $1 \mathrm{M}$ of vinyl acetate was set into an NMR tube with a cap. $20 \mathrm{~mL} \mathrm{~min}^{-1}$ of normal hydrogen was bubbled for $30 \mathrm{~s}$ at $30{ }^{\circ} \mathrm{C}$ and ${ }^{1} \mathrm{H}$ NMR spectrum was measured. A series of hydrogen bubbling and ${ }^{1} \mathrm{H}$ NMR measurement was repeated at least 5 times. Catalysts containing Cy ligands were completely activated within $30 \mathrm{~s}$, but it took 30-60 s for $[\mathrm{Rh}(\mathrm{nbd})(\mathrm{dppb})] \mathrm{BF}_{4}$ (cat 1) to be completely activated. Therefore, $\Delta \mathrm{mM}$ (product concentration) from $60 \mathrm{~s}$ (cat 1) and $\Delta \mathrm{mM}$ from $30 \mathrm{~s}$ (cat 2-5) were plotted.

\section{Hyperpolarization experiments}

General information. Methanol- $d_{4}$ was degassed by $\mathrm{N}_{2}$ bubbling just before experiments. NMR spectra were measured using a JEOL ECS400 spectrometer. 92\% para-enriched hydrogen was produced using Bruker ParaHydrogen Generator. Magnetic field cycling (MFC) systems were prepared according to a previous report. ${ }^{8}$ Polarization level was determined according to the procedure reported previously. ${ }^{8 a}$ 
(a)

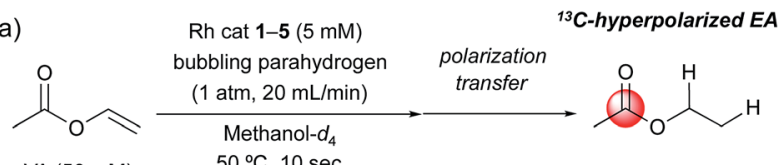
VA (50 mM) $\quad 50^{\circ} \mathrm{C}, 10 \mathrm{sec}$

(b)

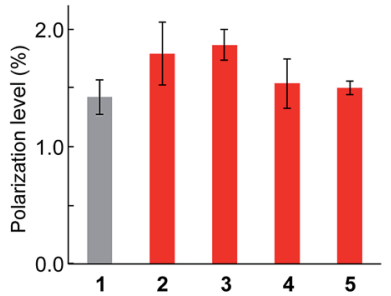

(c)

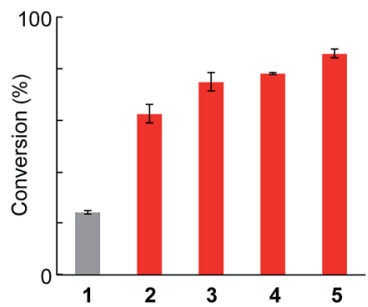

(d)

(e)

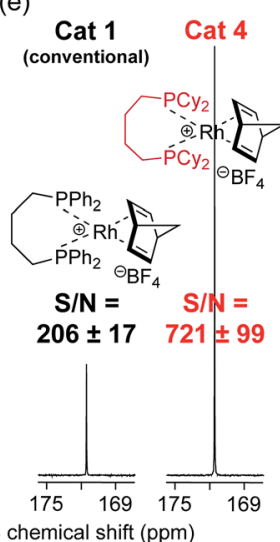

(f)

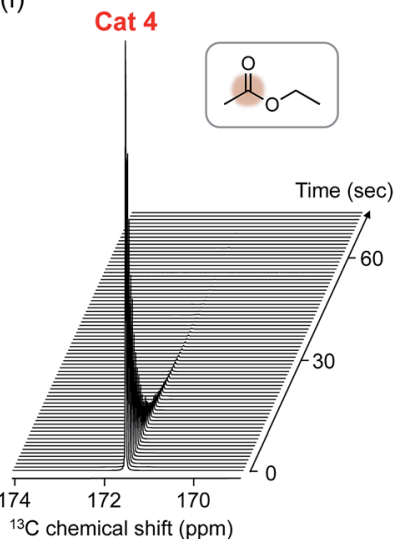

Fig. 2 (a) Conditions of the PHIP experiment of VA. (b) Polarization level $\% P^{{ }^{13} \mathrm{C}}$ at carbonyl carbon of EA. (c) Conversion rate of VA to EA. (d) ${ }^{13} \mathrm{C}$ NMR spectrum of natural abundant EA (ca. $40 \mathrm{mM}$ ) in thermal equilibrium state ( $30^{\circ}$ pulse, 1 scan). (e) ${ }^{13} \mathrm{C}$ NMR spectra ( $30^{\circ}$ pulse, 1 scan) of EA produced upon PHIP (initial concentration of VA $50 \mathrm{mM}$ ) with catalyst 1 or 4 . S/N means signal to noise ratio with standard deviation ( $n=3$ ). (f) Stacked ${ }^{13} \mathrm{C}$ NMR spectra of the hyperpolarized EA. PHIP experiments were conducted under the following conditions: 20 $\mathrm{mL} \min ^{-1}$ parahydrogen ( $1 \mathrm{~atm}$ ) was bubbled for $10 \mathrm{~s}$ into $700 \mu \mathrm{L}$ of methanol- $d_{4}$ containing $5 \mathrm{mM}$ catalyst and $50 \mathrm{mM}$ VA, followed by polarization transfer.

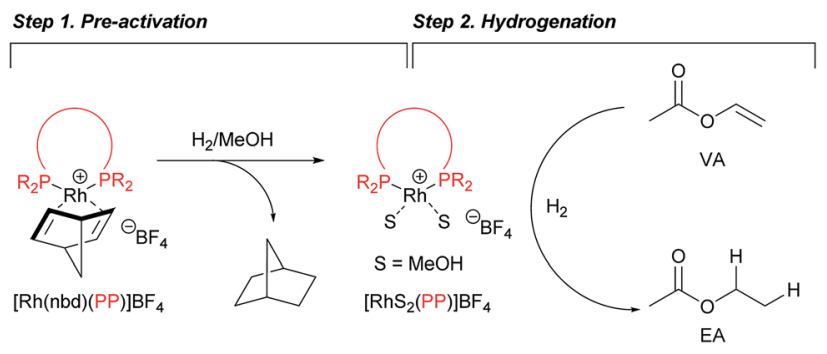

Scheme 2 Two steps of rhodium-catalysed hydrogenation.

PHIP experiment of vinyl acetate. $5 \mathrm{mM}$ of catalysts 1-5 and $50 \mathrm{mM}$ of vinyl acetate ( $35 \mu \mathrm{mol}$, natural abundant) in $700 \mu \mathrm{L}$ of methanol- $d_{4}$ was equipped in an NMR tube. Immediately after parahydrogen bubbling at $50{ }^{\circ} \mathrm{C}$ under $1 \mathrm{~atm}$ for $10 \mathrm{~s}$, field cycling procedure (the NMR tube was quickly dropped into MFC

apparatus and slowly pulled up out from the apparatus in about $4 \mathrm{~s}$ ) under $0.2 \mu \mathrm{T}$ was conducted to transfer hyperpolarization from ${ }^{1} \mathrm{H}$ to ${ }^{13} \mathrm{C}$. The data represent mean values \pm s.d. for 3 samples.

PHIP experiment of propargyl acetate. $2.5 \mathrm{mM}$ of catalysts 15 and $50 \mathrm{mM}$ of propargyl acetate ( $35 \mu \mathrm{mol}$, natural abundant) in $700 \mu \mathrm{L}$ of methanol- $d_{4}$ was set in an NMR tube. Immediately after parahydrogen bubbling at $50{ }^{\circ} \mathrm{C}$ under $1 \mathrm{~atm}$ for $10 \mathrm{~s}$, field cycling procedure under $0.2 \mu \mathrm{T}$ was conducted to transfer hyperpolarization from ${ }^{1} \mathrm{H}$ to ${ }^{13} \mathrm{C}$. The data represent mean values \pm s.d. for 3 samples.

\section{Hyperpolarization using flow system}

General information. Methanol was degassed by $\mathrm{N}_{2}$ bubbling just before experiments. EYELA SynpleFlow MCR-1000 was used as a flow reactor. NMR spectra were measured using a JEOL ECS400 spectrometer. 92\% para-enriched hydrogen was produced using Bruker ParaHydrogen Generator. Magnetic field cycling (MFC) systems were prepared according to a previous report. ${ }^{8}$

Hyperpolarization using flow system. Catalyst 1 or 4 (5.0 $\mu \mathrm{mol}$, final concentration $5.0 \mathrm{mM})$ and vinyl acetate $(1.0 \mathrm{mmol}$, final concentration $1.0 \mathrm{M}$ ) were dissolved in $1 \mathrm{~mL}$ of degassed methanol. A column of the reactor was filled with sea sand and heated to $50{ }^{\circ} \mathrm{C}$. Back pressure was set to $0.39 \mathrm{MPa}$. After 3.0 $\mathrm{mL} \min ^{-1}$ of mobile phase (methanol) flowing and 100 $\mathrm{mL} \mathrm{min}^{-1}$ of $92 \%$ para-enriched hydrogen flowing became stable, the mixture of catalyst and substrate was injected to the flow reactor. The effluent was collected in an NMR tube and MFC was conducted to transfer hyperpolarization from ${ }^{1} \mathrm{H}$ to ${ }^{13} \mathrm{C}$. The data represent mean values \pm s.d. for 3 samples.

\section{Results and discussion}

\section{Initial ligand screening based on catalytic activity}

We commenced our evaluation of various rhodium catalysts in the hydrogenation of VA, which is a minimal model molecule usually applied to PHIP-SAH. ${ }^{10 a}$ All experiments were conducted in methanol or methanol- $d_{4}$ because most of the ligands were insoluble in water. We examined the hydrogenation of VA in the presence of rhodium complexes prepared in situ from $[\mathrm{Rh}(\mathrm{nbd})]_{2} \mathrm{BF}_{4}$ with various phosphine ligands (Scheme $\mathrm{S} 1 \dagger$ ). The reaction was carried out using a solution of VA in methanol$d_{4}(150 \mathrm{mM})$ with $5 \mathrm{mM}$ of rhodium catalyst, under constant

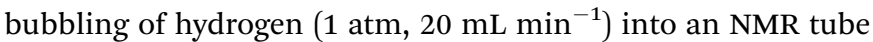
for $30 \mathrm{~s}$ at $50{ }^{\circ} \mathrm{C}$. The conversion rate was then determined by ${ }^{1} \mathrm{H}$ NMR analysis. Screening of various phosphine ligands revealed that highly electron-donating bisphosphine ligands with a dicyclohexylphosphino group ( $\mathrm{PCy}_{2}$ group) were particularly promising in terms of their catalytic activity (Table 1, entries 7-9 and 11).

\section{Hyperpolarization experiment of VA}

Based on the screening of ligands, we next prepared rhodium complexes $[\mathrm{Rh}(\mathrm{nbd})(\mathrm{dcpe})] \mathrm{BF}_{4} \quad(2),[\mathrm{Rh}(\mathrm{nbd})(\mathrm{dcpp})] \mathrm{BF}_{4} \quad$ (3), $[\mathrm{Rh}(\mathrm{nbd})(\mathrm{dcpb})] \mathrm{BF}_{4}(4)$ and $[\mathrm{Rh}(\mathrm{nbd})(\mathrm{dcpf})] \mathrm{BF}_{4}$ (5) (see Fig. 1b). 
(a)

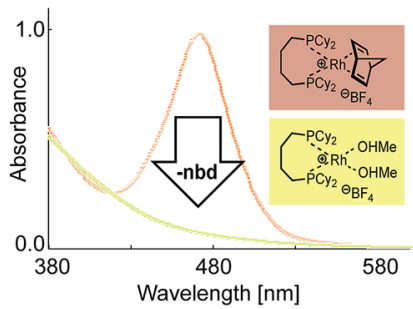

(b)

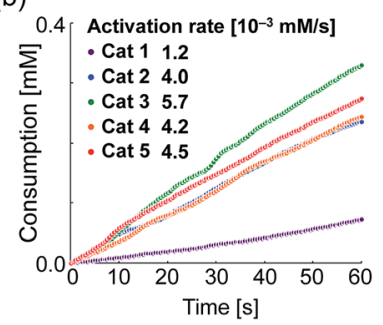

Fig. 3 Measurement of activation rates. (a) UV-vis spectra of $0.5 \mathrm{mM}$ of Rh-dcpb complex with and without nbd. (b) Determination of activation rates. Activation rates were determined by monitoring absorption around $470-480 \mathrm{~nm}$ of $0.5 \mathrm{mM}$ catalyst solution at $1 \mathrm{~atm}$ of hydrogen.

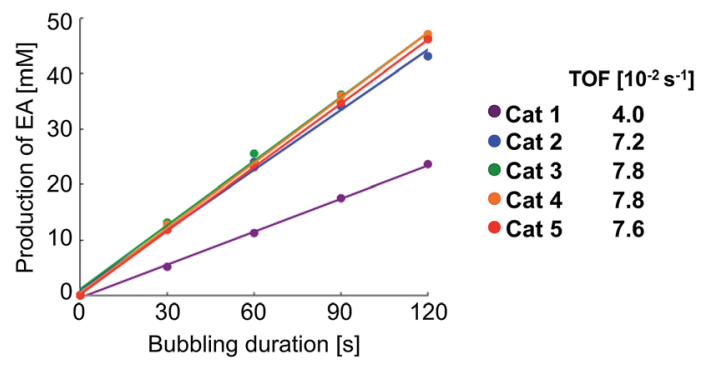

Fig. 4 TOF of Rh catalysts $1-5$ in hydrogenation for vinyl acetate (VA) Determination of TOF for VA (cat 1-5). $5 \mathrm{mM}$ of catalyst solution in methanol- $d_{4}$ containing $1 \mathrm{M}$ of VA was set into an NMR tube, and bubbled with normal hydrogen $\left(20 \mathrm{~mL} \mathrm{~min}^{-1}\right)$.

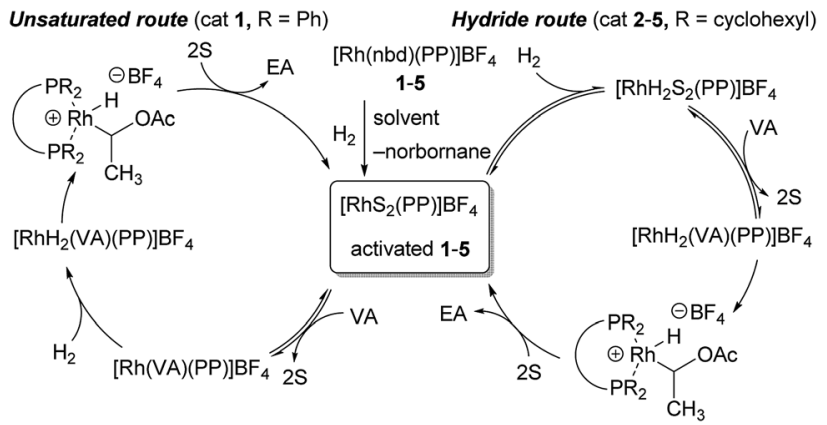

Fig. 5 Two different catalytic cycles of hydrogenation. nbd $=2,5$ norbornadiene, $\mathrm{S}=$ solvent, $\mathrm{VA}=$ vinyl acetate, $\mathrm{EA}=$ ethyl acetate, PP $=$ bisphosphine ligand.

Rhodium complexes of bisphosphine ligands with a dicyclohexylphosphino group have been reported as catalysts for hydrogenation; however, to our knowledge, they have not been widely employed for PHIP experiments. ${ }^{13}$

With these promising rhodium catalysts in hand, we conducted the PHIP-SAH experiment of VA according to procedure described by Chekmenev and co-workers. ${ }^{8 a}$ We performed our hyperpolarization experiment by bubbling parahydrogen $(1 \mathrm{~atm}, 20$ $\mathrm{mL} \mathrm{min}^{-1}$ ) for $10 \mathrm{~s}$ into a methanol- $d_{4}$ solution of ${ }^{13} \mathrm{C}$ natural abundance VA (50 mM) and rhodium catalysts 1-5 (5 mM) in NMR tubes at $50{ }^{\circ} \mathrm{C}$ under the Earth magnetic field. Then, the sample was quickly inserted in $0.2 \mu \mathrm{T}$ field and pulled out slowly ( $c a .4 \mathrm{~s}$ ) to transfer the hyperpolarization from nascent protons to ${ }^{13} \mathrm{C}$ with longer $T_{1}$ (ALTADENA conditions) (Fig. 2a and Scheme $\mathrm{S} 2 \dagger$ ). Our PHIP-SAH experiments of VA using catalysts 1-5 resulted in the successful observation of hyperpolarized ${ }^{13} \mathrm{C}$ NMR signals of ethyl acetate (EA). The polarization level $\% P^{{ }^{13} \mathrm{C}}$ at the carbonyl carbon of EA reached about $1.5 \%$, which was comparable in the case of conventional catalyst 1 and modified catalysts 2-5 (Fig. 2b). In contrast, the conversion rate of the hydrogenation with catalysts 25 was uniformly higher than that with 1 (Fig. $2 \mathrm{c}$ ). ${ }^{14}$ As a result, the signal-to-noise $(\mathrm{S} / \mathrm{N})$ ratios of the ${ }^{13} \mathrm{C}$ NMR signals obtained when using catalysts $\mathbf{2 - 5}$ were enhanced; they were three to four times higher than when using conventional catalysis $\mathbf{1}$ (Fig. 2d-f).

\section{Hydrogenation kinetics}

To gain further insight into the origin of the better catalytic activities of 2-5, we investigated the kinetics of the hydrogenation. In the initial stage of hydrogenation, the removal of the coordinated nbd ligand of 1-5 must be carried out to generate active species under reductive conditions (Step 1 in Scheme 2).

Thus, we first determined the activation rate of 1-5 under hydrogen $(1 \mathrm{~atm})$ by UV-Vis analysis of the coordinated nbd ligands, with the maximum absorption wavelength at 470$480 \mathrm{~nm}$ (Fig. 3a). Subsequently, the removal rate of a nbd ligand of modified catalysts $2-5$ was determined to be 4.0-5.7 $\times$ $10^{-3} \mathrm{mM} \mathrm{s}^{-1},{ }^{14}$ whereas that of 1 was $1.2 \times 10^{-3} \mathrm{mM} \mathrm{s}^{-1}$ (Fig. 3b).

Next, we checked the turnover frequency (TOF) of the completely activated rhodium catalysts in the hydrogenation of VA with bubbling of hydrogen (1 atm) (Step 2 in Scheme 2). The TOF of catalysts 2-5 was determined to be 1.8-2.0 times higher than that of 1 (Fig. 4). ${ }^{14}$ Overall, these two kinetic studies revealed that both catalyst activation (Step 1) and hydrogenation (Step 2) proceeded rapidly in the case of catalysts 2-5, resulting in higher performance in the PHIP experiments.

\section{Possible reaction mechanism}

To further consider the reasons for the high catalytic activity of 2-5, details of differences in each of the possible reaction mechanism are illustrated in Fig. 5. In the general pathway, with cationic rhodium catalysts such as $\mathbf{1}$, it is well known that hydrogenation takes place via the initial coordination of substrates before the oxidative addition of hydrogen, which is irreversible ${ }^{15}$ ('Unsaturated route', left in Fig. 5). ${ }^{16}$ In contrast, Imamoto and co-workers propose that cationic rhodium complexes $\left[\mathrm{RhS}_{2}(\mathrm{PP})\right] \mathrm{BF}_{4}$ with an electron-donating bisphosphine ligand bearing alkyl groups are first converted to the corresponding dihydride complexes $\left[\mathrm{RhH}_{2} \mathrm{~S}_{2}(\mathrm{PP})\right] \mathrm{BF}_{4}$, rather than the coordination of substrates, due to the stabilizing effect on the high oxidation state of a rhodium centre ('Hydride route', right in Fig. 5)..$^{17}$ It has been also examined that the reversible addition of hydrogen and ortho-para interconversion occur in the hydrogenation with catalyst 1 and the formation of rhodium hydride species is more favoured with the more basic phosphine ligands. ${ }^{18}$ In addition, 
(a)

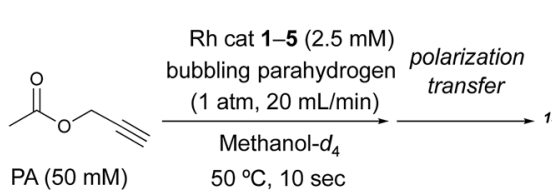

${ }^{13}$ C-hyperpolarized $A A$

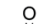

边

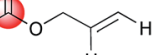

${ }^{13}$ C-hyperpolarized $n-P A$

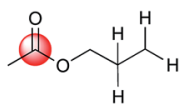

(b)

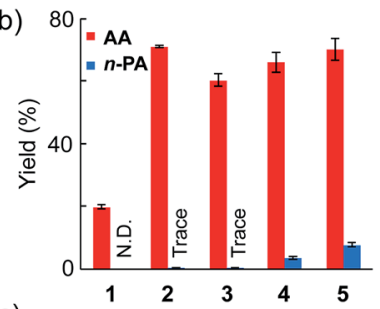

(d)

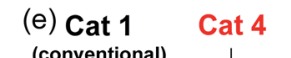

(c)

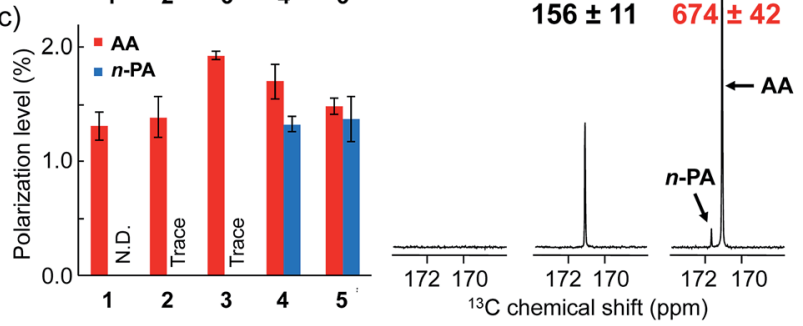

Fig. 6 (a) Conditions of PHIP experiment of PA. (b) Conversion rate of $P A$ to $A A$ and $n$-PA. (c) Polarization level $\% P^{13} \mathrm{C}$ at carbonyl carbon of AA and $n$-PA. (d) ${ }^{13} \mathrm{C}$ NMR spectrum of natural abundant AA (ca. $35 \mathrm{mM}$ ) in thermal equilibrium state $\left(30^{\circ}\right.$ pulse, 1 scan). (e) ${ }^{13} \mathrm{C}$ NMR spectra $\left(30^{\circ}\right.$ pulse, 1 scan) of AA and $n$-PA produced upon PHIP (initial concentration of PA $50 \mathrm{mM}$ ) with catalyst 1 or 4 . S/N means signal to noise ratio with standard deviation $(n=3)$. PHIP experiments were conducted under the following conditions: $20 \mathrm{~mL} \mathrm{~min}^{-1}$ parahydrogen (1 atm) was bubbled for $10 \mathrm{~s}$ into $700 \mu \mathrm{L}$ of methanol- $d_{4}$ containing $2.5 \mathrm{mM}$ catalyst and $50 \mathrm{mM}$ PA, followed by polarization transfer.

an isolation of the related stable cationic rhodium hydride complex of a bisphosphine ligand with a diisopropylphosphino group was reported. ${ }^{19}$ Thus, it may be possible to reason that hydrogenation with our modified catalysts 2-5 might proceed mainly via the Hydride route. ${ }^{6,20,21}$ It should be also noted that the Hydride route has been thought to be less preferable for PHIP. ${ }^{6,22}$ In our attempt to determine the plausible mechanism, the generation of the corresponding dihydride species after $\mathrm{H}_{2}$ bubbling with both catalysts $\mathbf{1}$ and 4 was observed (Fig. S1 $\dagger$ ). Therefore, further investigations, e.g., identification of the rate-determining step, are required

(a)

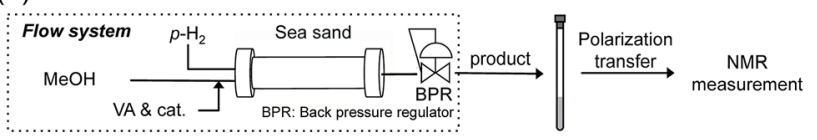

(b)

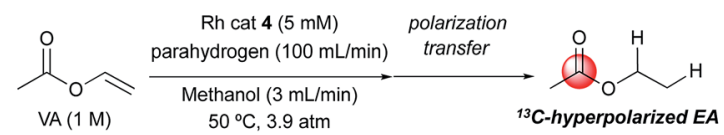

Fig. 7 (a) Illustration of flow hydrogenation system used in this study. (b) Reaction conditions for PHIP of VA in (a). to conclude which pathway would be more plausible for hydrogenation with catalysts $\mathbf{2 - 5}$.

\section{Hyperpolarization experiment of PA}

With high-performance catalysts in hand, we then moved to examine the hydrogenation of propargyl esters, which have also been employed for PHIP-SAH experiments (Fig. 6). ${ }^{9,20}$ Fig. 6b shows the conversion rate of the hydrogenation of a model compound, propargyl acetate (PA), to allyl acetate (AA). As in the case of VA, the yields of AA with 2-5 were uniformly higher than that with $\mathbf{1}$. In reactions with $\mathbf{2 - 5}$, double hydrogenation occurred to afford $n$-propyl acetate (n-PA), suggesting the stronger reductive ability of these rhodium catalysts. Thus, we demonstrated PHIP experiments of PA and observed the same or slightly higher level of hyperpolarization at the carbonyl carbon (Fig. 6c). Consequently, PHIP with catalyst 4 resulted in ${ }^{13} \mathrm{C}$ NMR signals that were about four times higher than with catalyst 1 (Fig. 6d and e).

\section{Hyperpolarization using flow system}

Finally, we tried to apply these rhodium catalysts to flow hydrogenation systems ${ }^{23}$ to achieve continuous acquisition of hyperpolarized samples in high concentration. We conducted PHIP-SAH of $1 \mathrm{M}$ VA in methanol using a flow reactor in a combined phase of $100 \mathrm{~mL}$ min $^{-1}$ parahydrogen and 3 $\mathrm{mL} \min ^{-1}$ substrate in methanol, as illustrated in Fig. 7. When using one of the modified catalysts 4, the PHIP experiment yielded a high concentration of $\mathrm{EA}(c a .300 \mathrm{mM})$ with a polarization level of $\sim 0.7 \%$. Because of the slightly longer operation time, in comparison with the batch reaction system, the polarization level $\% P^{{ }^{13} \mathrm{C}}$ at the carbonyl carbon of $\mathrm{EA}$ was slightly lower. Further improvements of a flow reactor, specifically in terms of a shorter reaction pathway, would be helpful in producing large amounts of product with higher polarization efficiency.

\section{Conclusions}

In conclusion, we investigated structural modification of the conventional rhodium catalyst $\mathbf{1}$ for PHIP experiments based on a screening approach of organometallic chemistry. We found that the modified catalyst candidates 2-5 with electrondonating bisphosphine ligands, with a dicyclohexylphosphino group, resulted in faster hydrogenation, with the same polarization level, under our experimental conditions $\left(50{ }^{\circ} \mathrm{C}\right.$, parahydrogen $1 \mathrm{~atm}$, continuous parahydrogen bubbling), thus leading to higher ${ }^{13} \mathrm{C}$ NMR signals. To further demonstrate the utility of these catalysts, we used them in PHIP-SAH experiments of VA in liquid-gas two-phase flow systems. Here, we recorded the production of hyperpolarized EA in significantly high concentration $(c a .300 \mathrm{mM})$. It should be noted that in this study we evaluated and optimized ligands based on the catalytic hydrogenation activity. Further screening study focusing on hyperpolarization efficiency, especially retention of para spin during the catalytic reaction, would allow finding better catalysts for PHIP. 


\section{Conflicts of interest}

There are no conflicts to declare.

\section{Acknowledgements}

This work was supported by CREST (JPMJCR13L4), Japan Science and Technology Agency. We thank Dr F. Reineri of the University of Torino for experimental support and helpful discussions. We also thank Prof. Dr K. Nozaki and Dr S. Kusumoto of the University of Tokyo for their kind donation of phosphine ligands and carrying out NMR measurement.

\section{Notes and references}

1 (a) A. Viale and S. Aime, Curr. Opin. Chem. Biol., 2010, 14, 90; (b) A. Viale, F. Reineri, D. Santelia, E. Cerutti, S. Ellena, R. Gobetto and S. Aime, Q. J. Nucl. Med. Mol. Imaging, 2009, 53, 604 .

2 A. Bornet, R. Melzi, A. J. P. Linde, P. Hautle, B. van den Brandt, S. Jannin and G. Bodenhausen, J. Phys. Chem. Lett., 2013, 4, 111.

3 (a) M. G. Pravica and D. P. Weitekamp, Chem. Phys. Lett., 1988, 145, 255; (b) C. R. Bowers and D. P. Weitekamp, J. Am. Chem. Soc., 1987, 109, 5541; (c) T. C. Eisenschmid, R. U. Kirss, P. P. Deutsch, S. I. Hommeltoft and R. Eisenberg, J. Am. Chem. Soc., 1987, 109, 8089; (d) C. R. Bowers and D. P. Weitekamp, Chem. Phys. Lett., 1986, 57, 2645.

4 R. W. Adams, J. A. Aguilar, K. D. Atkinson, M. J. Cowley, P. I. P. Elliott, S. B. Duckett, G. G. R. Green, I. G. Khazal, J. López-Serrano and D. C. Williamson, Science, 2009, 323, 1708.

5 Recent efforts for designing long $T_{1}$ structures, see for example: (a) Y. Imakura, H. Nonaka, Y. Takakusagi, K. Ichikawa, N. R. Maptue, A. M. Funk, C. Khemtong and S. Sando, Chem.-Asian J., 2018, 13, 280; (b) H. Nonaka, M. Hirano, Y. Imakura, Y. Takakusagi, K. Ichikawa and S. Sando, Sci. Rep., 2017, 7, 40104; (c) H. Nonaka, R. Hata, T. Doura, T. Nishihara, K. Kumagai, M. Akakabe, M. Tsuda, K. Ichikawa and S. Sando, Nat. Commun., 2013, 4, 2411; (d) T. Doura, R. Hata, H. Nonaka, K. Ichikawa and S. Sando, Angew. Chem., Int. Ed., 2012, 51, 10114.

6 (a) E. Cavallari, C. Carrera and F. Reineri, Isr. J. Chem., 2017, 57, 833; (b) J. B. Hçvener, A. N. Pravdivtsev, B. Kidd, C. R. Bowers, S. Glçggler, K. V. Kovtunov, M. Plaumann, R. Katz-Brull, K. Buckenmaier, A. Jerschow, F. Reineri, T. Theis, R. V. Shchepin, S. Wagner, P. Bhattacharya, N. M. Zacharias and E. Y. Chekmenev, Angew. Chem., Int. Ed., 2018, 57, 11140.

7 PHIP using heterogeneous catalysts were also reported, see for example: (a) I. V. Koptyug, K. V. Kovtunov, S. R. Burt, M. S. Anwar, C. Hilty, S.-I. Han, A. Pines and R. Z. Sagdeev, J. Am. Chem. Soc., 2007, 129, 5580; (b) S. Glçggler, A. M. Grunfeld, Y. N. Ertas, J. McCormick, S. Wagner, P. P. M. Schleker and L.-S. Bouchard, Angew. Chem., Int. Ed., 2015, 54, 2452; (c) E. W. Zhao, H. Zheng, R. Zhou,
H. E. Hagelin-Weaver and C. R. Bowers, Angew. Chem., Int. Ed., 2015, 54, 14270.

8 (a) R. V. Shchepin, D. A. Barskiy, A. M. Coffey, I. V. Manzanera Esteve and E. Y. Chekmenev, Angew. Chem., Int. Ed., 2016, 55, 6071; (b) K. V. Kovtunov, D. A. Barsliy, R. V. Shchepin, A. M. Coffey, K. W. Waddell, I. V. Koptyug and E. Y. Chekmenev, Anal. Chem., 2014, 86, 6192.

9 (a) M. Roth, Sensitivity enhancement in NMR by using parahydrogen induced polarization, PhD thesis, Johannes Gutenberg-Universität Mainz, 2010; (b) R. V. Shchepin, A. M. Coffey, K. W. Waddell and E. Y. Chekmenev, J. Phys. Chem. Lett., 2012, 3, 3281.

10 (a) F. Reineri, T. Boi and S. Aime, Nat. Commun., 2015, 6, 5858; (b) N. V. Chukanov, O. G. Salnikov, R. V. Shchepin, K. V. Kovtunov, I. V. Koptyug and E. Y. Chekmenev, ACS Omega, 2018, 3, 6673; (c) O. G. Salnikov, R. V. Shchepin, N. V. Chukanov, L. Jaigirdar, W. Pham, K. V. Kovtunov, I. V. Koptyug and E. Y. Chekmenev, J. Phys. Chem. C, 2018, 122, 24740.

11 K. Golman, R. I. Zandt and M. Thaning, Proc. Natl. Acad. Sci. U. S. A., 2006, 103, 11270.

12 D. Heller, S. Barns, W. Baumann and R. Selke, Chem. Ber., 1996, 129, 85.

13 (a) H.-J. Drexler, W. Baumann, A. Spannenberg, C. Fisher and D. Heller, J. Organomet. Chem., 2001, 621, 89; (b) H. G. Nedden, WO Pat., 2010001173A1, 2010.

14 Activities among catalysts $\mathbf{2}-\mathbf{5}$ could not be differentiated with sufficient statistical significances. Therefore, precise comparison among catalysts $\mathbf{2 - 5}$ is not discussed in this research.

15 F. Reineri, S. Aime, R. Gobetto and C. Nervi, J. Chem. Phys., 2014, 140, 094307.

16 R. A. Sánchez-Delgado and M. Rosales, Coord. Chem. Rev., 2000, 196, 249.

17 (a) I. D. Gridnev, N. Higashi, K. Asakura and T. Imamoto, J. Am. Chem. Soc., 2000, 122, 7183; (b) I. D. Gridnev, Y. Yamanoi, N. Higashi, H. Tsuruta, M. Yasutake and T. Imamoto, Adv. Synth. Catal., 2001, 343, 118; (c) T. Imamoto, K. Tamura, Z. Zhang, Y. Horiuchi, M. Sugiya, K. Yoshida, A. Yanagisawa and I. D. Gridnev, J. Am. Chem. Soc., 2012, 134, 1754; (d) I. D. Gridnev and T. Imamoto, Acc. Chem. Res., 2004, 37, 633; (e) I. D. Gridnev and T. Imamoto, Chem. Commun., 2009, 7447; $(f)$ T. Imamoto, Chem. Rec., 2016, 16, 2659.

18 J. M. Brown, L. R. Canning, A. J. Downs and A. M. Forster, J. Organomet. Chem., 1983, 255, 103.

19 K. Tani, T. Yamagata, Y. Tatsuno, T. Saito, Y. Yamagata and N. Yasuoka, J. Chem. Soc., Chem. Commun., 1986, 494.

20 E. Cavallari, C. Carrera, S. Aime and F. Reineri, Chem.-Eur. J., 2017, 23, 1200.

21 PHIP experiments with the conventional neutral rhodium complex such as $\mathrm{RhCl}\left(\mathrm{PPh}_{3}\right)_{3}$ (Wilkinson's catalyst) showed poor polarization levels because the reversible addition of parahydrogen was included, see: R. U. Kirss and R. Eisenberg, J. Organomet. Chem., 1989, 359, C22. 
22 Under high pressure PHIP in a batch system, relatively lower $\% P^{13} \mathrm{C}$ values were observed for cat 4 (data not shown) than for cat $\mathbf{1}$. This may be attributed to ortho-para conversion in the 'Hydride route'.

23 Examples of PHIP experiments using flow systems, see: $(a)$ L.-S. Bouchard, S. R. Burt, M. S. Anwar, K. V. Kovtunov, I. V. Koptyug and A. Pines, Science, 2008, 319, 442; (b) V.-V. Telkki, V. V. Zhivonitko, S. Ahola, K. V. Kovtunov,
J. Jokisaari and I. V. Koptyug, Angew. Chem., Int. Ed., 2010, 49, 8363; (c) K. V. Kovtunov, V. V. Zhivonitko, I. V. Skovpin, D. A. Barskiy, O. G. Salnikov and I. V. Koptyug, J. Phys. Chem. C, 2013, 117, 22887; (d) D. A. Barskiy, O. G. Salnikov, K. V. Kovtunov and I. V. Koptyug, J. Phys. Chem. A, 2015, 119, 996; (e) O. G. Salnikov, K. V. Kovtunov and I. V. Koptyug, Sci. Rep., 2015, 5, 13930. 